\title{
Criterion for trismus in head and neck cancer patients: a verification study
}

\author{
Sarah J. van der Geer ${ }^{1}$ Phillip V. van Rijn ${ }^{1}$ • Jolanda I. Kamstra ${ }^{1}$ • Jan L. N. Roodenburg ${ }^{1}$ • Pieter U. Dijkstra ${ }^{1,2}$
}

Received: 23 January 2018 / Accepted: 3 August 2018 / Published online: 14 August 2018

(C) The Author(s) 2018

\begin{abstract}
Purpose Several cut-off points for trismus in head and neck cancer patients have been used. A mouth opening of $35 \mathrm{~mm}$ or less is most frequently used as cut-off point. Due to the variation in cut-off points, prevalence, risk factors and treatment outcomes of trismus cannot be studied in a uniform manner. To provide uniformity, we aimed to verify the cut-off point of $35 \mathrm{~mm}$ or less. Additionally, we aimed to determine associated covariates with reported difficulties when opening the mouth.

Methods In a cross-sectional design, we measured the mouth opening in 671 head and neck cancer patients at the Department of Oral and Maxillofacial Surgery, at the University Medical Center Groningen. The cut-off point was determined using the receiver operating characteristic curve and Youden index, with reported difficulties when opening the mouth as criterion for trismus. Cutoff points for significant covariates were also determined.

Results The Youden index was highest at $35 \mathrm{~mm}$, with a sensitivity of 0.71 and a specificity of 0.86 . Of the covariates analysed, type of treatment modality was significantly associated with reported difficulties when opening the mouth. The highest Youden index for patients treated with surgery alone was $37 \mathrm{~mm}$ and for patients treated with radiotherapy alone $33 \mathrm{~mm}$.

Conclusions The cut-off point of $35 \mathrm{~mm}$ or less for trismus was confirmed in a head and neck cancer population and is recommended to be used in future studies. Patients receiving different treatment modalities experience difficulty when opening the mouth differently.
\end{abstract}

Keywords Head and neck neoplasms · Mouth neoplasms · Surgery, oral · Trismus · Range of motion, articular · Quality of life

\section{Introduction}

Trismus, a restricted mouth opening, in head and neck cancer patients may be caused by ingrowth of the tumour in the masticatory muscles or by fibrosis after surgery or radiotherapy. Trismus can hamper normal oral intake, dental hygiene, social activities, oncological follow-up and dental treatment [1-5].

Different cut-off points have been described for trismus based on the dental status of patients: $35 \mathrm{~mm}$ for dentulous

Sarah J. van der Geer

s.j.van.der.geer@umcg.nl

1 Department of Oral and Maxillofacial Surgery, University of Groningen, University Medical Center Groningen, Hanzeplein 1, 9713 GZ Groningen, The Netherlands

2 Department of Rehabilitation, University of Groningen, University Medical Center Groningen, Hanzeplein 1, 9713

GZ Groningen, The Netherlands patients and $40 \mathrm{~mm}$ for edentulous patients [2]. Other cut-off points for trismus are based on the severity of the restriction, such as $35 \mathrm{~mm}$ for moderate trismus and 20 or $25 \mathrm{~mm}$ for severe trismus $[6,7]$. Based upon the severity of the restriction, grades have also been used: grade 2 for a mouth opening of 10 to $20 \mathrm{~mm}$, grade 3 for a mouth opening of 5 to $10 \mathrm{~mm}$ and grade 4 for a mouth opening less than $5 \mathrm{~mm}$ [8]. Sometimes cut-off points seem to be chosen arbitrarily [9]. Due to the various cut-off points used, risk factors and the effectiveness of treatment for trismus cannot be analysed in a uniform manner and research results cannot be interpreted easily.

The most commonly used cut-off point is $35 \mathrm{~mm}$ or less [1, 10-12]. A study determined this cut-off point on the basis of perceived restrictions reported by head and neck cancer patients [13]. The percentage correctly predicted trismus was $81 \%$, with a sensitivity of 0.71 and a specificity of 0.98 . Another study had a similar cut-off point of less than $35 \mathrm{~mm}$ based upon reported problems with chewing and diet [14]. The sample sizes were 89 and 100 patients, resulting in little or no statistical power to perform covariate analyses. 
The aim of the present study was to verify the cut-off point of $35 \mathrm{~mm}$ or less for trismus in a large head and neck cancer population. Firstly, we determined the cut-off point for trismus based upon reported difficulties opening the mouth. Secondly, we determined cut-off points for significant covariates.

\section{Materials and methods}

\section{Patient selection}

This cross-sectional study included patients who visited the Department of Oral and Maxillofacial Surgery at the University Medical Center Groningen (UMCG) (Netherlands) for head and neck cancer between November 2012 and January 2015. Patients were included if they had a malignant tumour located in the upper aero-digestive tract, unknown primaries with metastases in the head and neck region, or a major salivary gland tumour. Patients were excluded if they were younger than 18 years, were not diagnosed with head and neck cancer, had rare types of tumours, had missing data regarding maximum mouth opening (MMO) or had missing data regarding reported difficulties opening the mouth.

Our study was carried out according to the regulations of our institute. The Medical Ethical Committee of the UMCG concluded that our research was not subject to the Medical Research (Human Subject) Act (METc number 2016.692).

\section{MMO measurements and difficulties opening the mouth}

MMO measurements were performed by surgeons, nurse practitioners or residents, using the OraStretch ${ }^{\circledR}$ Range-ofMotion Scale, as part of routine patient care. MMO was measured during every follow-up visit. As patients had several follow-up visits during the study period, multiple MMO measurements were recorded. In our analysis, we used only the first recorded MMO measurement of each included patient. MMO and dental status were recorded on a separate registration form. If the mouth opening was measured at the right upper central incisor and the right lower central incisor (of own dentition or prosthesis), the dental status was recorded as 'dentate'. If the alveolar ridges at the former location of the right upper and lower central incisor were used as measurement points, the dental status was recorded as 'edentulous'.

If the alveolar ridge was used as the measurement point for one jaw, and the right upper or lower central incisor for the other jaw, the dental status was recorded as 'partially edentulous'. Because the scale of the OraStretch $®$ Range-of-Motion Scale has a maximum of $52 \mathrm{~mm}$, patients who had a MMO of $52 \mathrm{~mm}$ or more were measured using a sliding calliper (mm). After recording the MMO, the patients were asked if they experienced difficulties opening the mouth (yes, no).

\section{Additional data}

Besides the data on the registration form, additional data was retrieved from the patient information system used in the UMCG, including cT classification based on the Union for International Cancer Control (UICC) TNM classification 2009 (TX, T1-2, T3-4, unknown), tumour localisation (tongue, floor of mouth, maxilla (including the maxilla, hard palate and maxillary sinus), mandible, cheek, major salivary glands (including the parotid gland, submandibular gland and sublingual gland), oropharynx (including the oropharynx, base of tongue, retromolar space, tonsils and soft palate), hypopharynx and larynx, lip, unknown primary) and treatment modalities (no treatment, surgery alone, radiotherapy alone, combination of surgery and radiotherapy). Patients were recorded as having received radiotherapy if they received primary radiotherapy or a combination of radiotherapy and chemotherapy.

\section{Primary analysis}

Data was analysed using a receiver operating characteristic (ROC) curve, in which MMO was compared to the patients' reported difficulties opening the mouth. Based on the ROC curve, we calculated the AUC, sensitivity, specificity and Youden index. We determined the discriminant validity of patients reporting difficulties opening the mouth to be perfect if the area under the curve (AUC) was 1 , highly accurate if $\geq 0.9$, moderately accurate if $0.7 \geq$ AUC $<0.9$, less accurate if $0.5 \geq \mathrm{AUC}<0.7$ and noninformative if the AUC was 0.5 [15]. The Youden index was calculated as follows: (sensitivity + specificity) -1 [16]. We determined a cut-off point for trismus on the basis of the highest Youden index score.

\section{Covariate analysis}

We used a $t$ test for independent samples to analyse an association between reported difficulties opening the mouth and age and a $\chi^{2}$ test to analyse associations between reported difficulties opening the mouth and sex, dental status and different treatment modalities. When a significant association between reported difficulties opening the mouth and a covariate was found $(p<0.05)$, separate ROC curves were plotted for that covariate. Cut-off points for the subgroups of that covariate were determined in the same way as for the total group.

\section{Post hoc analysis}

In case the results of the performed analyses need more clarification or insight in the data, additional analyses were performed. 


\section{Results}

\section{Patient characteristics}

MMO of 839 patients was recorded. In total, 168 patients were excluded because they were not diagnosed with head and neck cancer $(n=77)$, had rare types of tumours concerning localisations (for example pyriform sinus, ethmoid sinus, sphenoid sinus), metastases of primary tumours that were not part of head and neck oncology (for example mamma or kidney), or histology (neuroblastoma, lymphoma, Merkel cell carcinoma) or a combination $(n=29)$, or had missing data regarding MMO measurement or reported difficulties opening the mouth $(n=62)$. In total, 134 patients had a MMO larger than $52 \mathrm{~mm}$, of whom 109 were measured using a sliding calliper. Of 25 patients, the MMO was set on $52 \mathrm{~mm}$ because a sliding calliper was unavailable during the visit. The final study population consisted of 671 patients $(80.0 \%)$ (Table 1$)$. In our final study population, 278 patients $(41.4 \%)$ were treated with surgery alone, 130 patients $(19.4 \%)$ were treated with radiotherapy alone and 215 patients $(32.1 \%)$ were treated with a combination of surgery and radiotherapy.

\section{MMO measurements versus difficulties opening the mouth}

In total, 109 (16.2\%) patients reported difficulties opening the mouth. These patients had a mean MMO of $30.1 \mathrm{~mm}(95 \%$ confidence interval (CI) 28.0 to $32.1 \mathrm{~mm}$ ) (Fig. 1a). Patients
Table 1 Patient, tumour and treatment characteristics

\begin{tabular}{|c|c|c|c|}
\hline & Total $(n=671)$ & $\begin{array}{l}\text { Surgery only } \\
(n=278)\end{array}$ & $\begin{array}{l}\text { Radiotherapy only } \\
(n=130)\end{array}$ \\
\hline Patient characteristics & $n(\%)$ & $n(\%)$ & $n(\%)$ \\
\hline Male & $360(53.7)$ & $143(51.4)$ & $82(63.1)$ \\
\hline Age (years), range 11-96 (mean; SD) & $63.4(13.5)$ & $62.6(13.7)$ & $63.9(11.3)$ \\
\hline Maximum mouth opening, range 7-73 (mean; SD) & $42.2(10.6)$ & $45.0(8.8)$ & $41.3(11.1)$ \\
\hline \multicolumn{4}{|l|}{ Dental status } \\
\hline Fully dentulous & $526(78.4)$ & $234(84.2)$ & $95(73.1)$ \\
\hline Fully edentulous & 99 (14.8) & $33(11.9)$ & $25(19.2)$ \\
\hline Partially edentulous & $42(6.3)$ & $9(3.2)$ & $10(7.7)$ \\
\hline Missing & $4(0.6)$ & $2(0.7)$ & $0(0.0)$ \\
\hline \multicolumn{4}{|l|}{ Tumour characteristics } \\
\hline \multicolumn{4}{|l|}{ Localisation of primary tumour } \\
\hline Tongue & $148(22.1)$ & $89(32.0)$ & $7(5.4)$ \\
\hline Floor of mouth & $82(12.2)$ & $39(14.0)$ & $13(10.0)$ \\
\hline Maxilla & $34(5.1)$ & $17(6.1)$ & $7(5.4)$ \\
\hline Mandible & $49(7.3)$ & $23(8.3)$ & $1(0.8)$ \\
\hline Cheek & $19(2.8)$ & $8(2.9)$ & $1(0.8)$ \\
\hline Major salivary glands & $70(10.4)$ & $30(10.8)$ & $5(3.8)$ \\
\hline Oropharynx & $94(14.0)$ & $24(8.6)$ & 45 (34.6) \\
\hline Hypopharynx and larynx & $32(4.8)$ & $0(0.0)$ & $24(18.5)$ \\
\hline Lip & $52(7.7)$ & $27(9.7)$ & $14(10.8)$ \\
\hline Unknown primary & $12(1.8)$ & $2(0.7)$ & $8(6.2)$ \\
\hline Missing & $79(11.8)$ & $19(6.8)$ & $5(3.8)$ \\
\hline \multicolumn{4}{|l|}{ T classification } \\
\hline $\mathrm{TX}$ & $9(1.3)$ & $1(0.4)$ & $2(1.5)$ \\
\hline $\mathrm{T} 1, \mathrm{~T} 2$ & $410(61.1)$ & $230(82.7)$ & $60(46.2)$ \\
\hline $\mathrm{T} 3, \mathrm{~T} 4$ & $143(21.3)$ & $18(6.5)$ & $56(43.1)$ \\
\hline Missing & $109(16.2)$ & $29(10.4)$ & $12(9.2)$ \\
\hline \multicolumn{4}{|l|}{ Treatment characteristics } \\
\hline No treatment & $48(7.2)$ & $0(0.0)$ & $0(0.0)$ \\
\hline Surgery & $278(41.4)$ & $278(100.0)$ & $0(0.0)$ \\
\hline Radiotherapy & $130(19.4)$ & $0(0.0)$ & $130(100.0)$ \\
\hline Combination of surgery and radiotherapy & $215(32.1)$ & $0(0.0)$ & $0(0.0)$ \\
\hline
\end{tabular}




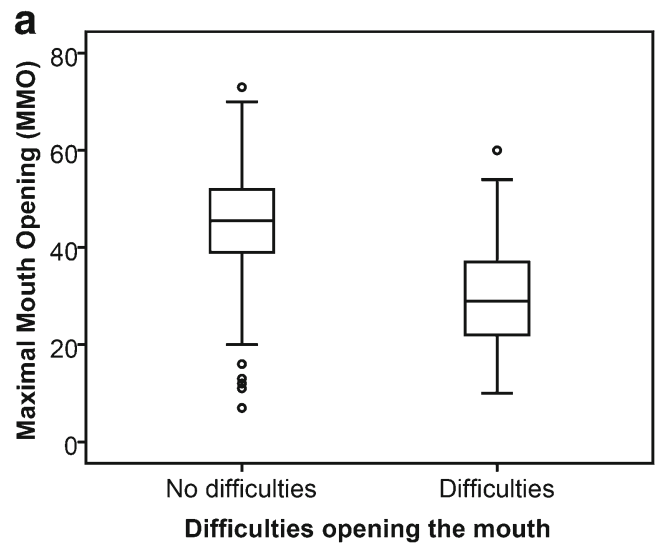

b

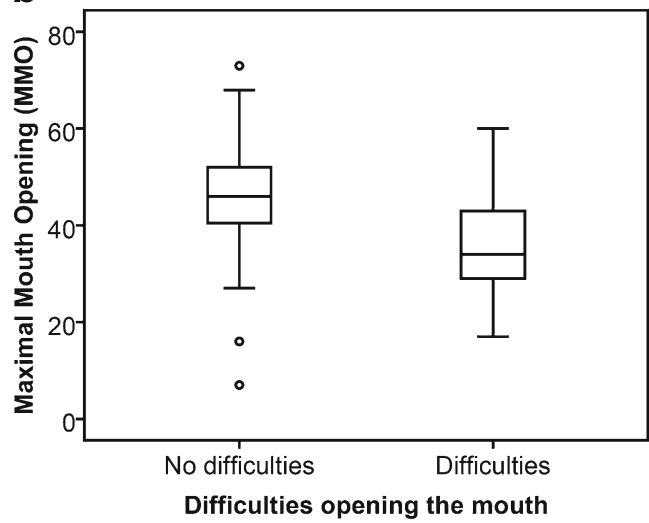

C

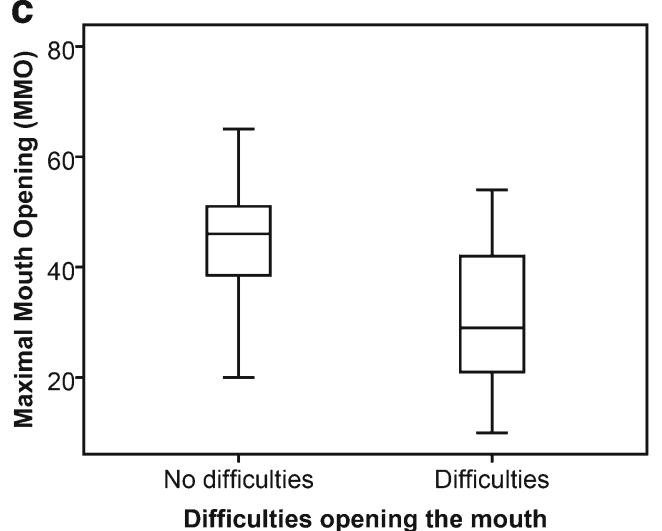

Fig. 1 Box-and-whisker plots concerning maximum mouth opening in relation to patients' perception of experiencing difficulties opening the mouth. a Total study population, b patients treated with surgery only, c patients treated with radiotherapy only

who reported no difficulties opening the mouth had a mean MMO of $44.5 \mathrm{~mm}$ (95\% CI 43.8 to $45.2 \mathrm{~mm}$ ).

\section{Primary analysis}

The AUC of the ROC curve of the total study population was 0.846 (95\% CI 0.803 to 0.889 ) (Fig. 2a). The Youden index was highest at $35 \mathrm{~mm}(0.569)$ with a sensitivity of 0.706 and a specificity of 0.863 (Table 2).
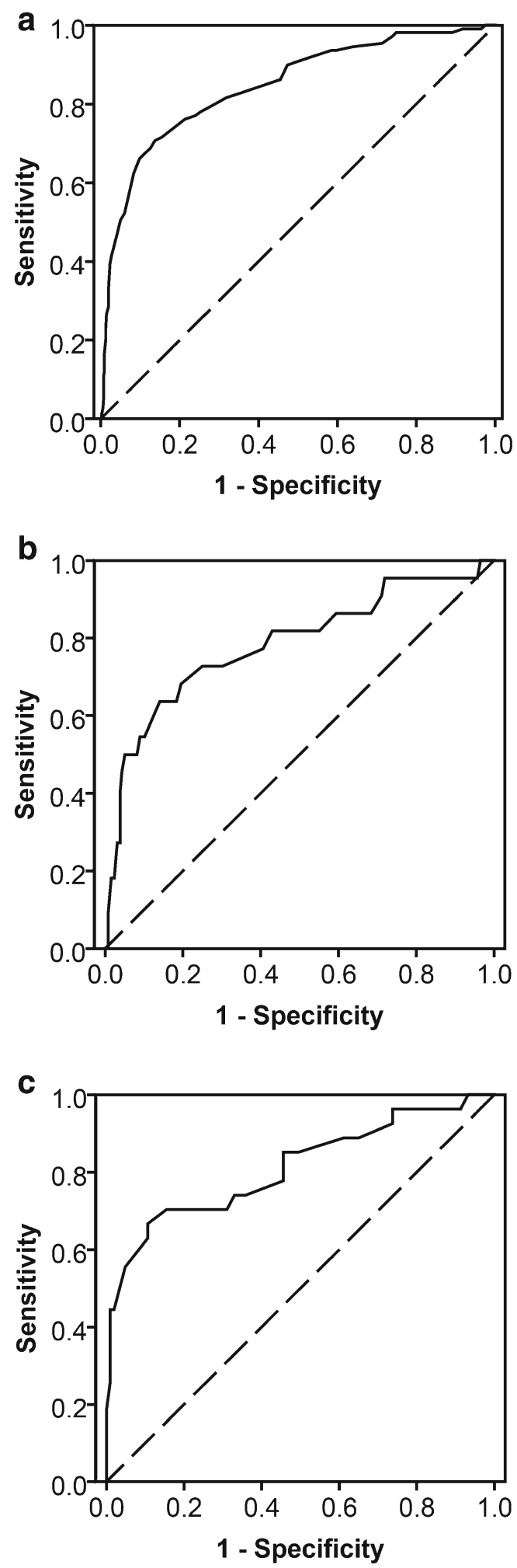

Fig. 2 Receiver operating characteristic curve comparing maximum mouth opening $(\mathrm{mm})$ with reported difficulties opening the mouth. a ROC curve for the total study population. Area under the curve: 0.846 (95\% CI 0.803 to 0.889 ). b ROC curve for surgery only. Area under the curve: 0.784 (95\% CI 0.667 to 0.901). c ROC curve for radiotherapy only. Area under the curve: 0.811 (95\% CI 0.705 to 0.917 ) 
Table 2 Sensitivity, specificity and Youden index for maximum mouth opening measurements

\begin{tabular}{|c|c|c|c|c|c|c|c|c|c|}
\hline \multirow{2}{*}{$\begin{array}{l}\text { Cut-off point } \\
(\mathrm{mm})\end{array}$} & \multicolumn{3}{|c|}{ Total study population $(n=671)$} & \multicolumn{3}{|c|}{ Surgery only $(n=278)$} & \multicolumn{3}{|c|}{ Radiotherapy only $(n=130)$} \\
\hline & Sensitivity & Specificity & $J$ & Sensitivity & Specificity & $J$ & Sensitivity & Specificity & $J$ \\
\hline 20 & 0.202 & 0.988 & 0.189 & 0.091 & 0.992 & 0.083 & 0.259 & 0.990 & 0.250 \\
\hline 21 & 0.229 & 0.988 & 0.217 & 0.091 & 0.992 & 0.083 & 0.259 & 0.990 & 0.250 \\
\hline 22 & 0.266 & 0.986 & 0.252 & 0.091 & 0.992 & 0.083 & 0.370 & 0.990 & 0.361 \\
\hline 23 & 0.284 & 0.980 & 0.265 & 0.091 & 0.992 & 0.083 & 0.370 & 0.990 & 0.361 \\
\hline 24 & 0.312 & 0.980 & 0.292 & 0.091 & 0.992 & 0.083 & 0.407 & 0.990 & 0.398 \\
\hline 25 & 0.330 & 0.980 & 0.311 & 0.091 & 0.992 & 0.083 & 0.444 & 0.990 & 0.435 \\
\hline 26 & 0.394 & 0.977 & 0.371 & 0.091 & 0.992 & 0.083 & 0.444 & 0.981 & 0.425 \\
\hline 27 & 0.413 & 0.973 & 0.386 & 0.182 & 0.984 & 0.166 & 0.444 & 0.981 & 0.425 \\
\hline 28 & 0.468 & 0.959 & 0.427 & 0.182 & 0.977 & 0.158 & 0.481 & 0.971 & 0.452 \\
\hline 29 & 0.505 & 0.950 & 0.455 & 0.273 & 0.969 & 0.241 & 0.519 & 0.961 & 0.480 \\
\hline 30 & 0.523 & 0.940 & 0.462 & 0.273 & 0.961 & 0.234 & 0.556 & 0.951 & 0.507 \\
\hline 31 & 0.624 & 0.916 & 0.540 & 0.409 & 0.961 & 0.370 & 0.630 & 0.893 & 0.523 \\
\hline 32 & 0.642 & 0.909 & 0.551 & 0.455 & 0.957 & 0.412 & 0.630 & 0.893 & 0.523 \\
\hline 33 & 0.661 & 0.902 & 0.563 & 0.500 & 0.949 & 0.449 & 0.667 & 0.893 & $0.560^{\mathrm{a}}$ \\
\hline 34 & 0.688 & 0.874 & 0.562 & 0.500 & 0.918 & 0.418 & 0.704 & 0.845 & 0.548 \\
\hline 35 & 0.706 & 0.863 & $0.569^{\mathrm{a}}$ & 0.545 & 0.910 & 0.456 & 0.704 & 0.835 & 0.539 \\
\hline 36 & 0.716 & 0.845 & 0.561 & 0.545 & 0.898 & 0.444 & 0.704 & 0.816 & 0.519 \\
\hline 37 & 0.761 & 0.786 & 0.548 & 0.636 & 0.859 & $0.496^{\mathrm{a}}$ & 0.704 & 0.767 & 0.471 \\
\hline 38 & 0.771 & 0.760 & 0.530 & 0.636 & 0.816 & 0.453 & 0.704 & 0.748 & 0.451 \\
\hline 39 & 0.780 & 0.747 & 0.527 & 0.682 & 0.805 & 0.487 & 0.704 & 0.718 & 0.422 \\
\hline 40 & 0.807 & 0.698 & 0.505 & 0.727 & 0.750 & 0.477 & 0.704 & 0.689 & 0.393 \\
\hline 41 & 0.817 & 0.681 & 0.498 & 0.727 & 0.730 & 0.458 & 0.741 & 0.670 & 0.411 \\
\hline 42 & 0.826 & 0.653 & 0.479 & 0.727 & 0.699 & 0.426 & 0.741 & 0.641 & 0.382 \\
\hline 43 & 0.862 & 0.544 & 0.407 & 0.773 & 0.594 & 0.366 & 0.778 & 0.544 & 0.321 \\
\hline 44 & 0.899 & 0.527 & 0.426 & 0.818 & 0.570 & 0.388 & 0.852 & 0.544 & 0.396 \\
\hline 45 & 0.908 & 0.500 & 0.408 & 0.818 & 0.547 & 0.365 & 0.852 & 0.505 & 0.357 \\
\hline
\end{tabular}

$J$ Youden index

${ }^{\text {a }}$ Highest Youden index score

\section{Covariate analysis}

No significant difference in age was found between patients who reported difficulties opening the mouth and those who $\operatorname{did}$ not $(p=0.804)$. No significant difference was found in sex $(p=0.756)$ and in dental status $(p=0.439)$ between patients who reported difficulties opening the mouth and those who did not. Patients who were treated with radiotherapy alone experienced difficulties opening the mouth more often than patients who were treated with surgery alone $(p<0.001)$ (Table 3).

We plotted a ROC curve for patients who were treated with surgery alone and patients who were treated with radiotherapy alone (Fig. 2b, c). The AUC of the ROC curve for surgery alone was 0.784 (95\% CI 0.667 to 0.901 ). The Youden index was highest at a MMO of $37 \mathrm{~mm}(0.496)$, with a sensitivity of 0.636 and a specificity of 0.859 (Table 2). The AUC of the ROC curve for radiotherapy alone was
0.811 (95\% CI 0.705 to 0.917 ). The Youden index was highest at a MMO of $33 \mathrm{~mm}(0.560)$, with a sensitivity of 0.667 and a specificity of 0.893 .

\section{Post hoc analysis}

To provide insight into the possible association between the time from treatment (surgery or radiotherapy) to measurement and reported difficulties opening the mouth (yes, no), we performed additional analysis. Mann-Whitney $U$ test showed that the period from treatment to measurement differs significantly in relation to reported difficulties opening the mouth $(p=0.010)$ and in relation to treatment modality (surgery or radiotherapy) $(p<0.001)$ (Table 4$)$. In the multivariate logistic regression analysis, treatment modality was significantly associated with reported difficulties opening the mouth ( $p=0.005)$, but the period from treatment to measurement does not $(p=0.569)$. 
Table 3 Comparison between patients with and without difficulties opening the mouth

\begin{tabular}{|c|c|c|c|c|c|c|c|}
\hline & \multicolumn{2}{|c|}{$\begin{array}{l}\text { No difficulties } \\
\text { opening the mouth } \\
(n=562)\end{array}$} & \multicolumn{2}{|c|}{$\begin{array}{l}\text { Difficulties } \\
\text { opening the mouth } \\
(n=109)\end{array}$} & \multirow[b]{2}{*}{$\chi^{2}$} & \multirow[b]{2}{*}{$d f$} & \multirow[b]{2}{*}{$p$} \\
\hline & $n$ & $\%$ & $n$ & $\%$ & & & \\
\hline Male sex & 303 & 53.9 & 57 & 52.3 & 0.096 & 1 & 0.756 \\
\hline Dental status & & & & & 1.646 & 2 & 0.439 \\
\hline Dentate & 445 & 79.7 & 81 & 74.3 & & & \\
\hline Partially edentulous & 34 & 6.1 & 8 & 7.3 & & & \\
\hline Edentulous & 79 & 14.2 & 20 & 18.3 & & & \\
\hline Treatment modality & & & & & 33.528 & 3 & $<0.001$ \\
\hline No treatment & 44 & 7.8 & 4 & 3.7 & & & \\
\hline Surgery only & 256 & 45.6 & 22 & 20.2 & & & \\
\hline Radiotherapy only & 103 & 18.3 & 27 & 24.8 & & & \\
\hline \multirow[t]{2}{*}{ Surgery and radiotherapy } & 159 & 28.3 & 56 & 51.4 & & & \\
\hline & Mean & $\mathrm{SD}$ & Mean & SD & $\mathrm{DM}$ & $95 \% \mathrm{CI}$ & $p$ \\
\hline Age & 63.4 & 13.7 & 63.7 & 12.4 & -0.35 & -3.1 to 2.4 & $0.804^{\mathrm{a}}$ \\
\hline
\end{tabular}

$\%$ column percentage, $\chi^{2}$ results of chi-square test, $d f$ degrees of freedom, $D M$ difference in means

${ }^{\mathrm{a}} t$ test for independent samples
As we found a 4-mm difference between the cut-off points for different treatment modalities, we performed a Mann-Whitney $U$ test in order to give insight into a possible association between treatment modalities and the influence on MMO. The test showed that the MMO was not significantly different after surgery alone or radiotherapy alone for the patients who reported difficulties when opening the mouth $(p=0.078)$ (Table 4).

Table 4 Analysis of time from treatment to measurement (months) in patients with and without difficulties opening the mouth and in patients who had surgery only or radiotherapy only and analysis of maximal

\section{Discussion}

\section{Key results}

For the total study population, the cut-off point for trismus was $35 \mathrm{~mm}$ or less. For patients who were treated with surgery alone, the cut-off point was $37 \mathrm{~mm}$ or less and for patients who received radiotherapy alone $33 \mathrm{~mm}$ or less. mouth opening measurement, only of patients who reported difficulties when opening the mouth, who had surgery only or radiotherapy only, using the Mann-Whitney $U$ test

\begin{tabular}{|c|c|c|c|c|c|c|}
\hline & \multicolumn{2}{|c|}{$\begin{array}{l}\text { No difficulties opening the } \\
\text { mouth }(n=399)\end{array}$} & \multicolumn{2}{|c|}{$\begin{array}{l}\text { Difficulties opening the } \\
\text { mouth }(n=92)\end{array}$} & \multirow[b]{2}{*}{ MWU } & \multirow[b]{2}{*}{$p$} \\
\hline & Median & IQR & Median & IQR & & \\
\hline \multirow{3}{*}{$\begin{array}{l}\text { Time from treatment } \\
\text { to measurement }{ }^{\mathrm{a}}\end{array}$} & 28.2 & $8.9 ; 58.3$ & 16.1 & $2.1 ; 48.0$ & $15,174.0$ & 0.010 \\
\hline & \multicolumn{2}{|c|}{ Surgery only $(n=220)$} & \multicolumn{2}{|c|}{ Radiotherapy only $(n=80)$} & & \\
\hline & Median & IQR & Median & IQR & MWU & $p$ \\
\hline \multirow{3}{*}{$\begin{array}{l}\text { Time from treatment } \\
\text { to measurement }{ }^{\mathrm{a}}\end{array}$} & 33.9 & $12.6 ; 67.4$ & 9.6 & $1.5 ; 31.7$ & 4856.5 & $<0.001$ \\
\hline & \multicolumn{2}{|c|}{ Surgery only $(n=22)$} & \multicolumn{2}{|c|}{ Radiotherapy only $(n=27)$} & & \\
\hline & Median & IQR & Median & IQR & MWU & $p$ \\
\hline $\begin{array}{l}\text { Maximal mouth opening } \\
\text { measurement }\end{array}$ & 34.0 & $29.0 ; 43.3$ & 29.0 & $20.0 ; 43.0$ & 209.5 & 0.078 \\
\hline
\end{tabular}

$I Q R$ interquartile range, $M W U$ Mann-Whitney $U$ test

${ }^{a} 48$ patients received no treatment, 132 received treatment after the measurement moment

${ }^{\mathrm{b}}$ Only the patients are included who reported difficulties when opening the mouth 


\section{Interpretation}

We found that patients who were treated with radiotherapy alone experienced difficulties opening the mouth at a smaller mouth opening $(33 \mathrm{~mm})$ compared to patients who were treated with surgery alone $(37 \mathrm{~mm})$. Postoperative symptoms, such as pain, scarring and trismus, are immediately noticeable for the patient. After radiotherapy, MMO decreases more gradually [17]. On average, during radiotherapy (first 9 weeks), the MMO decreased with $1.3 \%$ per month. In the first 9 months after radiotherapy, the MMO decreased $2.4 \%$ per month. Between 12 and 24 months after radiotherapy, the MMO decreased $0.2 \%$ per month. This gradual decrease in MMO was also confirmed in another study [18]. The prevalence of trismus in head and neck cancer patients after radiotherapy treatment was 31.9\% after 3 months, 34.04\% after 6 months and $38.39 \%$ after 12 months. As the MMO decreases gradually, patients have the ability to adapt in the meantime and therefore may experience mouth opening restrictions at a smaller mouth opening.

Our assumption that patients adapt to limited mouth opening in time is confirmed in our data, as the period from treatment to measurement is significantly associated with reported difficulties opening the mouth. Taking the treatment modality into account, in a multivariate logistic regression analysis, the period from treatment to measurement was not significantly associated with reported difficulties opening the mouth. Therefore, for clinical use, the treatment modality alone should be taken into account for perceived difficulties when opening the mouth.

We observed a 4-mm difference between the cut-off points of different treatment modalities, but we also found that MMO was not significantly different after surgery alone or radiotherapy alone for the patients who reported difficulties when opening the mouth. Therefore, we prefer to speak of a trend for earlier reporting of difficulties when opening the mouth in patients treated with surgery alone compared to patients receiving radiotherapy alone.

\section{Other studies}

One study also determined the cut-off of $35 \mathrm{~mm}$ or less. That study performed an additional covariate analyses for dental status only, but did not find a significant difference [13]. We were able to analyse other covariates: we found a significant difference regarding treatment modalities as covariates, but not for dental status. A second study determined the cut-off point for trismus on the basis of reported problems with chewing and diet. This study determined the cut-off point of less than $34 \mathrm{~mm}$. They determined the cut-off point in groups of $5 \mathrm{~mm}$ instead of $1 \mathrm{~mm}$, which could therefore have resulted into a different cut-off point compared to our study. They did not perform additional covariate analyses [14].

\section{Study limitations and strengths}

A limitation of our study is that MMO was measured at different time intervals in regard to the patients' cancer treatment, as MMO was measured during regular appointments at the Department of Oral and Maxillofacial Surgery of Groningen. For example, one patient had a measurement 3 months posttreatment, while another patient had a measurement 24 months post-treatment. This difference could have led to an underestimation of patients who reported difficulties opening the mouth, as some patients could already have adapted to their new MMO and would not report difficulties opening the mouth.

Another possible limitation is that several professionals measured maximum mouth opening, which could have introduced an inter-observer measurement error. Nonetheless, a previous study shows that inter-observer variability is minimal [19].

As the sliding calliper was not always available during the MMO measurements, 25 patients could not be measured. Their MMO was set on $52 \mathrm{~mm}$. We expect that the patients with a MMO larger than $52 \mathrm{~mm}$ do not experience difficulties when opening the mouth. The results of the mean MMO of patients who do not experience difficulties when opening the mouth might therefore be slightly lower than the actual mean MMO.

The strength of our study is the large study population and MMO measurements. Due to our large database, we were able to perform covariate analyses with enough statistical power. Due to our covariate analyses, we were able to make a distinction between the patients' perception of having difficulties when opening the mouth after receiving radiotherapy or surgery. Now clinicians can take into account that patients' perception of a restricted mouth opening differ after surgery or radiotherapy. As the cut-off point of $35 \mathrm{~mm}$ or less is now confirmed in a large head and neck cancer population, clinicians could use this cut-off point as an indicator to start preventive measures. We recommend to use this cut-off point for future research as well; to explore risk factors of trismus, to report prevalence of trismus and for evaluating the effectiveness of trismus treatment.

\section{Conclusion}

We have verified the cut-off point of $35 \mathrm{~mm}$ or less for trismus in the total head and neck cancer population. Patients receiving different treatment modalities could differ in their perception of difficulties in opening their mouth. To improve comparison of future studies concerning trismus in head and neck cancer patients, we recommend using the cut-off point of $35 \mathrm{~mm}$ or less. 


\section{Compliance with ethical standards}

Research involving human participants and/or animals Retrospective study: for this type of study formal consent is not required.

The Medical Ethical Committee of the UMCG concluded that our research was not subject to the Medical Research (Human Subject) Act (METc number 2016.692).
This article does not contain any studies with animals performed by any of the authors.

Conflict of interest None declared.

Data Corresponding author has full control of all primary data.

Corresponding author allows the journal to review the data if requested.

\section{Appendix}

Table 5 Tumour localisation according to the World Health Organization, International Classification of Diseases for Oncology, third edition, topographical codes

\begin{tabular}{lll}
\hline Localisation & Specific elements of this localisation & Code $^{\mathrm{a}}$ \\
\hline Tongue & & $\mathrm{C} 02$ (NOT lingual tonsil C02.4) \\
Floor of mouth & Maxilla & $\mathrm{C} 04$ \\
Maxilla & Hard palate & $\mathrm{C} 03.0$ \\
& Maxillary sinus & $\mathrm{C} 05.0, \mathrm{C} 05.8$ \\
& & $\mathrm{C} 31.0$ \\
Mandible & & $\mathrm{C} 03.1$ \\
& & $\mathrm{C} 41.1$ \\
Cheek & & $\mathrm{C} 06.0$ \\
Major salivary glands & Parotid gland & $\mathrm{C} 07.9$ \\
& Submandibular gland & $\mathrm{C} 08.0$ \\
Oropharynx & Sublingual gland & $\mathrm{C} 08.1$ \\
& Oropharynx & $\mathrm{C} 10$ \\
Base of tongue & $\mathrm{C} 01$ \\
Lnknown primary & Retromolar space & $\mathrm{C} 06.2$ \\
\hline Hypopharynx & Tonsils & $\mathrm{C} 09, \mathrm{C} 02.4$ \\
& Soft palate & $\mathrm{C} 05.1$ \\
& & $\mathrm{C} 13$ \\
& & $\mathrm{C} 32$ \\
& & $\mathrm{C} 00$ \\
& & $\mathrm{C} 80$ \\
\hline
\end{tabular}

${ }^{\text {a }}$ Localisation according to the World Health Organization, International Classification of Diseases for Oncology, third edition, topographical codes
Open Access This article is distributed under the terms of the Creative Commons Attribution-NonCommercial 4.0 International License (http:// creativecommons.org/licenses/by-nc/4.0/), which permits any noncommercial use, distribution, and reproduction in any medium, provided you give appropriate credit to the original author(s) and the source, provide a link to the Creative Commons license, and indicate if changes were made.

\section{References}

1. Weber C, Dommerich S, Pau HW, Kramp B (2010) Limited mouth opening after primary therapy of head and neck cancer. Oral Maxillofac Surg 14:169-173
2. Louise Kent M, Brennan MT, Noll JL, Fox PC, Burri SH, Hunter JC, Lockhart PB (2008) Radiation-induced trismus in head and neck cancer patients. Support Care Cancer 16:305-309

3. Van Cann EM, Dom M, Koole R, Merkx MA, Stoelinga PJ (2005) Health related quality of life after mandibular resection for oral and oropharyngeal squamous cell carcinoma. Oral Oncol 41:687-693

4. Bensadoun RJ, Riesenbeck D, Lockhart PB, Elting LS, Spijkervet FK, Brennan MT, Trismus Section, Oral Care Study Group, Multinational Association for Supportive Care in Cancer (MASCC)/International Society of Oral Oncology (ISOO) (2010) A systematic review of trismus induced by cancer therapies in head and neck cancer patients. Support Care Cancer 18:1033-1038

5. Melchers LJ, Van Weert E, Beurskens CHG, Reintsema H, Slagter AP, Roodenburg JLN, Dijkstra PU (2009) Exercise adherence in patients with trismus due to head and neck oncology: a qualitative study into the use of the Therabite®. Int J Oral Maxillofac Surg 38: 947-954 
6. Lindblom U, Garskog O, Kjellen E, Laurell G, Levring Jaghagen E, Wahlberg P, Zackrisson B, Nilsson P (2014) Radiation-induced trismus in the ARTSCAN head and neck trial. Acta Oncol 53: $620-627$

7. Steiner F, Evans J, Marsh R, Rigby P, James S, Sutherland K, Wickens R, Nedev N, Kelly B, Tan ST (2015) Mouth opening and trismus in patients undergoing curative treatment for head and neck cancer. Int J Oral Maxillofac Surg 44:292-296

8. Anonymous (1995) LENT SOMA tables. Radiother Oncol 35:17-60

9. Ozyar E, Cengiz M, Gurkaynak M, Atahan IL (2005) Trismus as a presenting symptom in nasopharyngeal carcinoma. Radiother Oncol 77:73-76

10. Kamstra JI, Dijkstra PU, van Leeuwen M, Roodenburg JL, Langendijk JA (2015) Mouth opening in patients irradiated for head and neck cancer: a prospective repeated measures study. Oral Oncol 51:548-555

11. Wetzels JW, Merkx MA, de Haan AF, Koole R, Speksnijder CM (2014) Maximum mouth opening and trismus in 143 patients treated for oral cancer: a 1-year prospective study. Head Neck 36:1754-1762

12. Gebre-Medhin M, Haghanegi M, Robert L, Kjellen E, Nilsson P (2016) Dose-volume analysis of radiation-induced trismus in head and neck cancer patients. Acta Oncol 55:1313-1317
13. Dijkstra PU, Huisman PM, Roodenburg JLN (2006) Criteria for trismus in head and neck oncology. Int J Oral Maxillofac Surg 35: 337-342

14. Scott B, Butterworth C, Lowe D, Rogers SN (2008) Factors associated with restricted mouth opening and its relationship to healthrelated quality of life in patients attending a maxillofacial oncology clinic. Oral Oncol 44:430-438

15. Swets JA (1988) Measuring the accuracy of diagnostic systems. Science 240:1285-1293

16. Schisterman EF, Perkins NJ, Liu A, Bondell H (2005) Optimal cutpoint and its corresponding Youden index to discriminate individuals using pooled blood samples. Epidemiology 16:73-81

17. Wang CJ, Huang EY, Hsu HC, Chen HC, Fang FM, Hsiung CY (2005) The degree and time-course assessment of radiation-induced trismus occurring after radiotherapy for nasopharyngeal cancer. Laryngoscope 115:1458-1460

18. Nagaraja S, Kadam SA, Selvaraj K, Ahmed I, Javarappa R (2016) Trismus in head and neck cancer patients treated by telecobalt and effect of early rehabilitation measures. J Cancer Res Ther 12:685-688

19. Jager-Wittenaar H, Dijkstra PU, Vissink A, van Oort RP, Roodenburg JLN (2009) Variation in repeated mouth-opening measurements in head and neck cancer patients with and without trismus. Int J Oral Maxillofac Surg 38:26-30 